\title{
The Analgesic Effect of Remifentanil on Propofol Injection Pain
}

\author{
Younghoon Jeon, M.D., Ph.D. ${ }^{*}$ Min Je Choi, M.D. ${ }^{\dagger}$ and Choon Hak Lim, M.D., Ph.D. ${ }^{\dagger}$ \\ *Department of Anesthesiology, Kyungpook National University School of Dentistry, Daegu, \\ ${ }^{\dagger}$ Department of Anesthesiology and Pain Medicine, Korea University College of Medicine, Seoul, Korea
}

\begin{abstract}
Background: Pain is a common side-effect of propofol injection. A remifentanil pretreatment has been reported to decrease the incidence and intensity of pain during a propofol injection and has been suggested to act through a central or peripheral effect. This trial was designed to explore the action site of remifentanil on reducing propofol injection pain, using the venous occlusion technique and a time interval between the applications of remifentanil and propofol.

Methods: This randomized, double-blind study was designed to explore the action site of remifentanil on reducing propofol injection pain in 200 patients scheduled for elective surgery. The peripheral properties were examined using the venous occlusion technique for $30 \mathrm{~s}$ while a $1 \mathrm{~min}$ time interval between remifentanil and propofol injections was allowed for the central effect. Before the propofol injection, group A was pretreated with remifentanil $(0.5 \mu \mathrm{g} /$ $\mathrm{kg}$ ) with a venous occlusion, group $\mathrm{B}$ with remifentanil and a 1 min interval, and group $\mathrm{C}$ with remifentanil with a venous occlusion and a $1 \mathrm{~min}$ interval. Pain severity was assessed using a four-point scale.

Results: 40 patients $(80 \%)$ complained of pain in the placebo group compared with $35(70 \%)$ in group A, 20 $(40 \%)$ in group $\mathrm{B}(\mathrm{p}<0.05)$ and $17(34 \%)$ in group $\mathrm{C}(\mathrm{p}<0.05)$. The incidence and severity of propofol injection pain were lower in groups $B$ and $C$ than in group $A(p<0.05)$. However, there was no significant difference between groups $\mathrm{B}$ and $\mathrm{C}$.

Conclusions: The remifentanil mediated analgesic effect occurs mainly through the central effect.
\end{abstract}

Key Words: injection, pain, propofol, remifentanil.

\section{INTRODUCTION}

Pain during a propofol injection is a common side-effect reported in $80-90 \%$ of patients when a vein on the dorsum of the hand is used.[1-3] The pain may be immediate or delayed within $10-20 \mathrm{~s}$ of the injection.[4] Immediate pain is believed to be the result of a direct irritant effect, whereas delayed pain probably results from an indirect effect through a kinin cascade.[5]

A pretreatment with opioids has been reported to have an analgesic effect on propofol-induced pain and it was suggested that the analgesic effect might be mediated through either central or peripheral effect.[6-11] This is because opioid receptors

Received on April 26, 2011, Revised on June 18, 2011 (1st), July 11, 2011 (2nd), Accepted on August 23, 2011

Correspondence to: Choon Hak Lim, Department of Anesthesiology and Pain Medicine, Korea University Medical Center, Anam-dong 5 ga, Sungbuk-gu, Seoul 136-705, Korea

Tel: 02-920-6639, Fax: 02-928-2275

E-mail: yourejoice@ korea.ac.kr are found not only in the dorsal root ganglia and central terminals of primary afferent nerves, but also in the peripheral sensory nerve fibers and their terminals.[12] However, it is conflicting that opioids work via peripheral effect. $[8,13]$

A remifentanil pretreatment has been reported to decrease the incidence and intensity of pain during a propofol injection and been suggested to act through a central or peripheral effect.[14] However, there are no reports showing whether the analgesic effect is mediated mainly through a central or peripheral effect during a propofol injection. Therefore, this randomized controlled trial was designed to explore the action site of remifentanil on reducing propofol injection pain, using the venous occlusion technique and the time interval from application of remifentanil and propofol.

\section{MATERIALS AND METHODS}

Written informed consent was obtained from the patients and the Ethics Committee approved the study protocol. We enrolled 
200 patients, ASA I and II, aged 18-65 years, scheduled for elective surgery under general anesthesia. Patients who had received sedative or analgesic medication within $24 \mathrm{hr}$ before surgery, patients with known allergies to any drugs, patients with renal, hepatic or cardiac problem, patients who had neurological deficits and psychiatric disorders, and those requiring a rapid sequence induction were excluded.

Premedication was not given. On arrival in the holding area of operation room, a 20-gauge cannula was inserted into a vein of dorsum of the patient's nondominant hand without lidocaine infiltration and attached to Ringer's lactate infusion. All the patients were monitored using an electrocardiogram, pulse oximetry, and non-invasive arterial pressure upon arrival at the operating theater. According to a computer-generated random number table, the patients were randomly allocated to one of the following four groups:

Group P (placebo): The patients received saline $2 \mathrm{ml}$ over $10 \mathrm{~s}$ without venous occlusion and $1 \mathrm{~min}$ later, propofol (Diprivan $^{\circledR}$, AstraZeneca, Italy) was injected through the intravenous cannula.

Group A: A pneumatic tourniquet was placed on the upper arm to produce a venous occlusion and then the patients received remifentanil (Ultiva ${ }^{\circledR}$, GlaxoSmithKline, UK) $0.5 \mu \mathrm{g} / \mathrm{kg}$ over $10 \mathrm{~s}$. After $30 \mathrm{~s}$, the occlusion was released and propofol was injected through the intravenous cannula.

Group B: The patients received remifentanil $0.5 \mu \mathrm{g} / \mathrm{kg}$ over $10 \mathrm{~s}$ without venous occlusion and $1 \mathrm{~min}$ later, propofol was injected through the intravenous cannula.

Group C: A pneumatic tourniquet was placed on the upper arm to produce a venous occlusion and then the patients received remifentanil $0.5 \mu \mathrm{g} / \mathrm{kg}$ over $10 \mathrm{~s}$. After $30 \mathrm{~s}$, the occlusion was released and $1 \mathrm{~min}$ later, propofol was injected through the intravenous cannula.

During a $10 \mathrm{~s}$ pause after the first $25 \%$ of the calculated propofol dose $(2 \mathrm{mg} / \mathrm{kg})$ had been given over $2 \mathrm{~s}$, the patients were asked standard questions regarding the level comfort with the injection. A study-blinded anesthesiologist evaluated the level of pain during the propofol injection using a four-point scale: $0=$ none (negative response to questioning), $1=$ mild pain (pain reported only in response to questioning without any behavioral signs), 2 = moderate pain (pain reported in response to questioning and accompanied by behavioral signs or pain reported spontaneously without questioning), and $3=$ severe pain (strong vocal response or response accompanied by facial grimacing, arm withdrawal, or tears).[6] If there was no spontaneous complaint of pain, patients were asked if they experienced any pain in the arm $20 \mathrm{~s}$ after the start of the injection. Thereafter, the induction of anesthesia continued with the remainder of the calculated propofol dose. After the loss of an eyelash reflex, the patients were intubated after the administration of rocuronium $0.6 \mathrm{mg} / \mathrm{kg}$. Anesthesia was maintained with sevoflurane $2.0-2.5 \mathrm{vol} \%$ and nitrous oxide $50 \%$ in oxygen. Any emergency events during induction were recorded (e.g. hypotension, arrhythmia, flushing). Within 24 hours after surgery, the injection site was also checked for any complications such as pain, edema, and a wheal and flare response by a researcher who was blinded to the group assignment.

The differences between the scores from the placebo group and the other groups was estimated to be 1.5 and with a 0.05 $\alpha$-error (two sided), which required a sample size of 44 per group yielding a power $>80 \%$.

Statistical analysis was carried out using SAS v8.1 (SAS Institute Inc., Cary, NC, USA) for Windows ${ }^{\circledR}$. Data are presented as number of patients or mean $\pm \mathrm{SD}$. The demographic data was compared using ANOVA. The incidence of injection pain was analyzed using a Fisher's exact test. A MantelHaenszel Chi-square and Wilcoxon rank sum test was used to analyze the pain score. Statistical significance was defined as $p$ $<0.05$.

\section{RESULTS}

Two hundred patients were enrolled in this study, which consisted of 94 males and 106 females. Age in group B and group $\mathrm{C}$ were significantly different compared to one in group

Table 1. Patient Demographics

\begin{tabular}{lcccc}
\hline \hline \multicolumn{1}{c}{ Groups } & $\mathrm{P}(\mathrm{n}=50)$ & $\mathrm{A}(\mathrm{n}=50)$ & $\mathrm{B}(\mathrm{n}=50)$ & $\mathrm{C}(\mathrm{n}=50)$ \\
\hline Age $(\mathrm{yr})$ & $43.0 \pm 14.5$ & $46.1 \pm 12.2$ & $38.1 \pm 13.0^{*}$ & $38.6 \pm 13.8^{*}$ \\
Sex $(\mathrm{M} / \mathrm{F})$ & $28 / 22$ & $26 / 24$ & $16 / 34$ & $24 / 26$ \\
Weight $(\mathrm{kg})$ & $63.6 \pm 11.1$ & $65.9 \pm 10.6$ & $61.0 \pm 10.8$ & $63.6 \pm 9.0$ \\
Height $(\mathrm{cm})$ & $166.2 \pm 9.4$ & $164.8 \pm 10.3$ & $162.0 \pm 9.2$ & $165.5 \pm 8.3$ \\
\hline
\end{tabular}

Values are expressed as mean $\pm \mathrm{SD}$ or number. ${ }^{*} \mathrm{p}<0.05$ vs. group A. 
Table 2. Assessment of Pain during the Intravenous Injection of Propofol

\begin{tabular}{lcccc}
\hline \multicolumn{1}{c}{ Groups } & $\mathrm{P}(\mathrm{n}=50)$ & $\mathrm{A}(\mathrm{n}=50)$ & $\mathrm{B}(\mathrm{n}=50)$ & $\mathrm{C}(\mathrm{n}=50)$ \\
\hline Any pain (\%) & $40(80)$ & $35(70)$ & $20(40)^{*}+$ & $17(34)^{*}$, \\
Grading of pain & 10 & 15 & $30^{*}$ & $33^{*}$ \\
None [0] & 15 & 18 & 13 & 14 \\
Mild [1] & 14 & 14 & 7 & $3^{*}$ \\
Moderate [2] & 11 & $3^{*}$ & $0^{*}$ & $0^{*}$ \\
Severe [3] & $1.5^{\dagger}$ & $1^{*}$ & $0^{*}+$ \\
Median score & & & \\
\hline
\end{tabular}

Group $\mathrm{P}$, the patients received normal saline $2 \mathrm{ml}$ before propofol was injected; group A, the patients received remifentanil $0.5 \mu \mathrm{g} / \mathrm{kg}$ with venous occlusion for $30 \mathrm{~s}$ before propofol was injected; group B, the patients received remifentanil $0.5 \mu \mathrm{g} / \mathrm{kg} 1 \mathrm{~min}$ before propofol was injected; and group $\mathrm{C}$, the patients received remifentanil $0.5 \mu \mathrm{g} / \mathrm{kg}$ with venous occlusion for $30 \mathrm{~s}$ and propofol was injected 1 min later. Values are number (proportion). ${ }^{*} \mathrm{p}<0.05$ vs. group $\mathrm{P} ;{ }^{\dagger} \mathrm{p}<0.05$ vs. group A.

A $(\mathrm{p}<0.05)$, however, the groups were similar with respect to gender, weight, and height (Table 1).

The incidence and severity of pain during the propofol injection in the four groups were shown (Table 2). In group $\mathrm{P}$, 40 patients $(80 \%)$ reported pain during propofol injection compared with $35(70 \%)$ in group A, $20(40 \%)$ in group B (p < $0.05)$, and $17(34 \%)$ in group $C(p<0.05)$. The incidence of injection pain was significantly lower in groups $\mathrm{B}$ and $\mathrm{C}$ than in group $\mathrm{A}$ ( $\mathrm{p}<0.05$, respectively). However, there was no significant difference between groups $\mathrm{B}$ and $\mathrm{C}$.

An analysis of the injection pain score (median), found that groups A (1), B (0), and C (0) had a significantly lower score than group $\mathrm{P}(1.5)(\mathrm{p}<0.05$, respectively). The pain score was significantly lower in groups $\mathrm{B}$ and $\mathrm{C}$ than in group A ( $\mathrm{p}$ $<0.05$, respectively). There was no significant difference in pain score between groups $\mathrm{B}$ and $\mathrm{C}$.

Complications such as hypotension, chest tightness or respiratory depression were not observed or complained after remifentanil injection and also pain, edema, or a wheal and flare response were not observed at the injection site within the first $24 \mathrm{hr}$ after surgery.

\section{DISCUSSION}

In this study, there was an $80 \%$ incidence of propofol injection pain. A pretreatment with $0.5 \mu \mathrm{g} / \mathrm{kg}$ remifentanil using venous occlusion techniques for $30 \mathrm{~s}$ was not effective in attenuating the pain associated with the propofol injection but a pretreatment with $0.5 \mu \mathrm{g} / \mathrm{kg}$ remifentanil $1 \mathrm{~min}$ before the propofol injection was effective, regardless of the use of a venous occlusion. This shows that the analgesic effect of remifentanil during the propofol injection might be associated with a mainly central effect and not with a peripheral effect.
Propofol-induced pain ranked seventh among the 33 low morbidity clinical outcomes determined by expert anesthesiologists when both the clinical importance and frequency are considered.[15] The propofol-induced pain can be immediate or delayed with a latency of between 10 and 20 s. Propofol belongs to the group of phenols that can irritate the skin, mucous membranes, and venous intima.[16] In addition, propofol activates the kallikrein-kinin system through an indirect action on the endothelium and releases bradykinin. This can produce venous dilation and hyperpermeability, which increases the level of contact between the aqueous phase of propofol and the free nerve endings, resulting in pain upon injection.[5]

Remifentanil is a piperidine-based opioid that acts as a $\mu$ receptor agonist. Remifentanil studies associated with propofol injection pain have reported various results on the incidence of pain according to the administration method, dose of remifentanil, and time interval between the remifentanil and propofol injections.[6,9,12,14,17,18] The remifentanil dose, $0.5 \mu \mathrm{g} / \mathrm{kg}$, was determined based on previous studies by Batra et al.[14] and a bolus administration method was chosen in order to exclude the peripheral effect which can be induced by the infusion method.

A venous occlusion using a rubber tourniquet is a useful model for examining the peripheral actions of a study drug in the absence of a central effect, which is similar to the modified Bier block.[8] Lillie et al.[19] reported that the initial analgesia obtained using the intravenous regional technique was due to a blockade of the small nerves or possibly nerve endings. A venous occlusion was performed for $30 \mathrm{~s}$ in this study. The duration of the venous occlusion was based on metaanalysis, which concluded that the optimal method for preventing propofol associated pain is to administer intravenous lidocaine while the tourniquet is applied to the forearm over a pe- 
riod of 30-120 s before the propofol injection.[20]

Pang et al.[8] examined the peripheral actions of fentanyl, morphine, meperidine, or lidocaine on propofol injection pain using a venous occlusion technique. They reported that only meperidine and lidocaine significantly reduced the incidence and intensity of propofol injection pain. Fentanyl and morphine did not reduce the incidence of pain but reduced its intensity,[8] which is similar to the present results. They suggested that the analgesic effect of meperidine might be mediated through a local anesthetic effect, which could possibly be related to its structural similarity to cocaine and tetracaine, not by the peripheral opioid receptor because of the failure of fentanyl, which is a more potent $\mu$ agonist than meperidine.[8]

Wrench et al.[13] also reported that alfentanil did not relieve the pain upon an injection with propofol through its action on the peripheral opioid receptors when alfentanil was limited to the forearm for $30 \mathrm{~s}$ before the induction of anesthesia. In group A, the pretreatment with remifentanil with a venous occlusion before the propofol injection was designed to have only peripheral effect. However, it did not reduce the incidence of pain, even though it reduced its severity.

In order to evaluate the central effect of remifentanil, a 1 min interval between the remifentanil and propofol injections was used because the effect-site concentration of remifentanil peaks at 1 min.[21] In group $B$, the patients were given remifentanil $1 \mathrm{~min}$ before the propofol injection. This pretreatment significantly reduced the incidence and severity of propofol injection pain $(\mathrm{p}<0.05)$. Group $\mathrm{C}$, in which the patients were given remifentanil with $30 \mathrm{~s}$ venous retention and a time interval of $1 \mathrm{~min}$, was designed to have both a peripheral and central effect. We hypothesized that if remifentanil mainly had a central effect, the analgesic effect on reducing the level of propofol-induced pain would be similar in the two groups. As expected, pretreatment with remifentanil with time interval effectively reduced propofol induced pain and there was no significant difference in incidence and severity of pain between groups $\mathrm{B}$ and $\mathrm{C}$. Therefore, we suggested that the analgesic effect of remifentanil on propofol induced pain occurred mainly through the central effect.

In conclusion, remifentanil $0.5 \mu \mathrm{g} / \mathrm{kg}$ with $1 \mathrm{~min}$ time interval between the remifentanil and propofol injections was effective in reducing both the incidence and severity propofol injection pain whereas remifentanil using venous retention only significantly reduced the severity of pain. The remifentanilmediated analgesic effect was shown to occur mainly through the central effect.

\section{REFERENCES}

1) Smith I, White PF, Nathanson M, Gouldson R: Propofol. An update on its clinical use. Anesthesiology 1994; 81: 1005-43.

2) Fujii $Y$, Nakayama M: A lidocaine/metoclopramide combination decreases pain on injection of propofol. Can J Anaesth 2005; 52: 474-7.

3) Cheong MA, Kim KS, Choi WJ: Ephedrine reduces the pain from propofol injection. Anesth Analg 2002; 95: 1293-6.

4) Briggs LP, Clarke RS, Dundee JW, Moore J, Bahar M, Wright PJ: Use of di-isopropyl phenol as main agent for short procedures. Br J Anaesth 1981; 53: 1197-202.

5) Scott RP, Saunders DA, Norman J: Propofol: clinical strategies for preventing the pain of injection. Anaesthesia 1988; 43: 492-4.

6) Roehm KD, Piper SN, Maleck WH, Boldt J: Prevention of propofol-induced injection pain by remifentanil: a placebo-controlled comparison with lidocaine. Anaesthesia 2003; 58: $165-70$.

7) Iyilikci L, Balkan BK, Gökel E, Günerli A, Ellidokuz H: The effects of alfentanil or remifentanil pretreatment on propofol injection pain. J Clin Anesth 2004; 16: 499-502.

8) Pang WW, Mok MS, Huang S, Hwang MH: The analgesic effect of fentanyl, morphine, meperidine, and lidocaine in the peripheral veins: a comparative study. Anesth Analg 1998; 86: 382-6.

9) Kwak K, Kim J, Park S, Lim D, Kim S, Baek W, et al: Reduction of pain on injection of propofol: combination of pretreatment of remifentanil and premixture of lidocaine with propofol. Eur J Anaesthesiol 2007; 24: 746-50.

10) Tan $\mathrm{CH}$, Onsiong MK: Pain on injection of propofol. Anaesthesia 1998; 53: 468-76.

11) Ahmad N, Choy CY, Aris EA, Balan S: Preventing the withdrawal response associated with rocuronium injection: a comparison of fentanyl with lidocaine. Anesth Analg 2005; 100: 987-90.

12) Fields HL, Emson PC, Leigh BK, Gilbert RF, Iversen LL: Multiple opiate receptor sites on primary afferent fibres. Nature 1980; 284: 351-3.

13) Wrench IJ, Girling KJ, Hobbs GJ: Alfentanil-mediated analgesia during propofol injection: no evidence for a peripheral action. Br J Anaesth 1996; 77: 162-4.

14) Batra YK, Al-Qattan AR, Ward VD, Kuriakose D, Ali SS, Alexander D: Remifentanil pretreatment for propofol injection pain in children. Can J Anaesth 2004; 51: 519-20.

15) Macario A, Weinger M, Truong $P$, Lee $M$ : Which clinical anesthesia outcomes are both common and important to avoid? The perspective of a panel of expert anesthesiologists. Anesth Analg 1999; 88: 1085-91.

16) Ambesh SP, Dubey PK, Sinha PK: Ondansetron pretreatment to alleviate pain on propofol injection: a randomized, controlled, double-blinded study. Anesth Analg 1999; 89: 197-9.

17) King SY, Davis FM, Wells JE, Murchison DJ, Pryor PJ: 
Lidocaine for the prevention of pain due to injection of propofol. Anesth Analg 1992; 74: 246-9.

18) Basaranoglu G, Erden V, Delatioglu H, Saitoglu L: Reduction of pain on injection of propofol using meperidine and remifentanil. Eur J Anaesthesiol 2005; 22: 890-2.

19) Lillie PE, Glynn CJ, Fenwick DG: Site of action of intravenous regional anesthesia. Anesthesiology 1984; 61: 507-10.
20) Picard $P$, Tramèr MR: Prevention of pain on injection with propofol: a quantitative systematic review. Anesth Analg 2000; 90: 963-9.

21) Glass PS, Gan TJ, Howell S: A review of the pharmacokinetics and pharmacodynamics of remifentanil. Anesth Analg 1999; 89(4 Suppl): S7-14. 